\title{
Exercise testing in pulmonary sarcoidosis
}

\author{
CG INGRAM, PATRICIA C REID, RN JOHNSTON \\ From the Department of Clinical Measurement, Ninewells Hospital and Medical School, Durdee
}

ABSTRACT The change in transfer coefficient $(\mathrm{KCO})$ with increasing heart rate during exercise was studied in 25 normal subjects and in 21 patients with pulmonary sarcoidosis. The slope of the Kco response against heart rate was found to be $0.0053 \mathrm{mmol} \mathrm{min}{ }^{-1} \mathrm{kPa}^{-1} 1^{-1}$ per beat in the normal group but in many of the patients was two standard deviations or more below this normal slope, even when their routine function tests were normal. This response of $\mathrm{Kco}$ to exercise is a more sensitive index of changed function than more routine function tests in pulmonary sarcoidosis.

Disturbance of pulmonary function in sarcoidosis has been investigated for more than 20 years, but the interrelationships between the pathological changes, the appearances in the chest radiographs, and the pulmonary function measurements in this disease are still uncertain. It has been clearly established that patients with pulmonary sarcoidosis may have a normal chest radiograph but still have a significant degree of disturbed function. ${ }^{1}$ Furthermore, in some patients where infiltration of the lungs has resolved in the radiograph, pulmonary function may remain disturbed or may even deteriorate. ${ }^{2} 3$ It is apparent from findings such as these that a significant degree of pulmonary involvement can occur in the presence of a normal chest radiograph. On the other hand, those with severe infiltration of the lungs, as judged by radiological appearances, may sometimes apparently have little impairment of lung function. ${ }^{4}$ These discrepancies between the chest radiograph and tests of function can give rise to problems when attempts are made to assess the effect on the disease of treatment with corticosteroids.

The aspects of lung function most commonly disturbed by sarcoidosis are gas transfer, lung compliance and less commonly airway resistance. In an analysis of the value of various lung function tests in sarcoidosis, Marshall and Karlish ${ }^{5}$ suggested that gas transfer was most easily measured by the single breath carbon monoxide transfer factor and that forced vital capacity, which correlated well with changes in lung stiffness in this disease, was a simple way to monitor changes in lung compliance. They further proposed that the forced expiratory volume in one second $\left(F E V_{1}\right)$ should be used as a simple test of airway resistance, although several authors have

Address for reprint requests: Dr CG Ingram, Ninewells Hospital, Dundee DD2 1UB. since shown that changes in small airways can occur in this disease in the presence of a normal $\mathrm{FEV}_{1 .}{ }^{6}$ ?

As all of these tests may remain normal in patients who have proven pulmonary sarcoidosis and may remain unchanged even when the activity of the disease changes spontaneously or with treatment, we decided to look for a more sensitive index of changing lung function. It has long been recognised that abnormalities of lung function not obvious at rest may become apparent during exercise, especially abnormalities of gas transfer. We chose, therefore, to study the effect of exercise on gas transfer in patients with pulmonary sarcoidosis, using as our index the change in the single breath transfer factor during exercise.

\section{Methods}

Twenty-five normal subjects (17 male and eight female) with a mean age of 31 years and no history of respiratory disease were studied in order to establish the normal changes in transfer factor during exercise. Each subject rested on a bicycle ergometer until the heart rate reached basal levels; the transfer factor was then measured using a standard technique. ${ }^{8}$ Preliminary tests had established that the subjects could breath-hold for eight seconds even after vigorous exercise and so this breath-holding time was used in all tests. A progressive exercise test was then carried out on the bicycle ergometer starting with a load of 17 watts for one minute and increasing the load by 17 watts every minute. The test was stopped when the patient was unable to continue pedalling. Transfer factor was measured on several occasions during this period of progressive exercise. On each occasion the subject was asked to stop pedalling, the heart rate was noted, and the transfer factor test 
Table 1 Clinical data

\begin{tabular}{|c|c|c|c|c|c|}
\hline Number & $\operatorname{Sex}$ & Age $(y r)$ & Year of diagnosis & Stage & Percentage of lung involved \\
\hline $1^{*}$ & $\mathbf{M}$ & 31 & 1973 & 13 & 30 \\
\hline 2 & $\mathbf{M}$ & 32 & 1979 & 2 & 50 \\
\hline 4 & $\mathbf{F}$ & 29 & 1977 & 3 & 40 \\
\hline 5 & $\mathbf{M}$ & 25 & 1975 & 3 (F) & 80 \\
\hline 6 & $\mathbf{F}$ & 33 & 1979 & 2 & 25 \\
\hline 7 & $\mathbf{M}$ & 51 & 1977 & 3 & 20 \\
\hline $9 *$ & $\mathbf{M}$ & 29 & 1976 & 1 & 0 \\
\hline 10 & F & 25 & 1979 & 2 & 70 \\
\hline 11 & $\mathbf{F}$ & 27 & 1978 & 1 & 0 \\
\hline 12 & $\mathbf{M}$ & 35 & 1970 & 3 (F) & 50 \\
\hline 13 & $\mathbf{F}$ & 48 & 1976 & 3 & 50 \\
\hline 14 & $\mathbf{F}$ & 40 & 1978 & 3 & 30 \\
\hline 15 & $\mathbf{F}$ & 31 & 1973 & 3 (F) & 20 \\
\hline 16 & $\mathbf{F}$ & 33 & 1979 & 2 & 5 \\
\hline 17 & $\mathbf{M}$ & 27 & 1976 & 2 & 10 \\
\hline 19 & $\mathbf{F}$ & 30 & 1979 & 2 & 15 \\
\hline 20 & $\mathbf{F}$ & 60 & 1978 & 3 & 20 \\
\hline 21 & $\mathbf{F}$ & 67 & 1978 & 3 & 30 \\
\hline
\end{tabular}

* No histological confirmation nor positive Kveim test.

(F) radiographic evidence of fibrosis.

carried out. The progressive exercise was continued immediately after each test.

Twenty-one patients with pulmonary sarcoidosis were available for study and in all except two there was either histological confirmation (in 13) and/or a positive Kveim test (in 10). The clinical data are summarised in table 1 . In the two patients without histological confirmation of the disease there were associated clinical signs to support the diagnosis of sarcoidosis and subsequent follow-up over at least four years supported the diagnosis. Thirteen patients were female and eight male and their mean age was 35 years. Eleven patients entered the study within one year of the known onset of the disease but in the remainder the disease had been present for two to eight years. The clinical staging of pulmonary involvement is that described by Siltzbach, ${ }^{9}$ where stage 1 denotes bilateral hilar adenopathy (BHA) with clear lung fields, stage 2 denotes BHA with lung involvement, and stage 3 lung involvement without BHA. An assessment of the extent of lung involvement depends on both the density and distribution of granulomata but an approximate estimate of disease area was obtained using a $1 \mathrm{~cm}$ square grid superimposed on the radiograph.

Forced expirations and static lung volumes were measured in each patient. Their transfer factors were measured at rest by the method used in the normal subjects, again using an eight-second breath-holding time. The exercise test for the patients was modified by not carrying it to exhaustion but stopping when the heart rate had reached $85 \%$ of predicted maximum. Exercise was stopped on two or three occasions to measure transfer factor at different heart rates.

\section{Results}

Although the inspired volume and breath-holding time were fixed for an individual subject in successive tests, some slight variation in the volume at which the breath was held did occasionally occur and to correct for this the results have all been expressed as transfer factor divided by alveolar volume, the transfer coefficient (Kco). The change in $\mathrm{Kco}$ during $\overrightarrow{\bar{O}}$ exercise in a typical normal subject is shown in the figure. It can be seen that $\mathrm{Kco}$ increases with increasing heart rate and continues to increase up to the maximum heart rate. The slope of the change was calculated for each subject by the method of least squares. The normal subjects were allocated according to age into three groups, $20-30$ years, $30-40$ years,

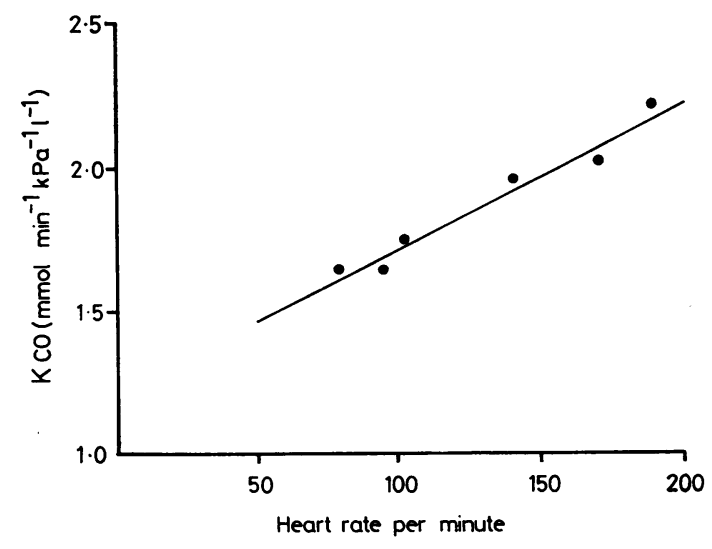

Figure Change in Kco during exercise in a typical normal subject. 
Table 2 Regression slopes for normal subjects

\begin{tabular}{llll}
\hline Age group & KCo slope & SD & Number \\
\hline $20-30$ & 0.0053 & 0.0005 & 10 \\
$31-40$ & 0.0051 & 0.0006 & 10 \\
$41-50$ & 0.0054 & 0.0006 & 5 \\
All subjects & 0.0053 & 0.0006 & 25 \\
\hline
\end{tabular}

and 40-50 years, and the mean slope for each age group is given in table 2. As there were no statistically significant differences between the mean slopes of these three groups, the data from them were pooled to give the mean slope for all normal subjects. This slope was $0.0053 \mathrm{mmol} \mathrm{min}-1 \mathrm{kPa}^{-1} \mathrm{l}^{-1}$ per beat, with a standard deviation of 0.0006 .

The results of function tests in the patients when first tested are presented in table 3 . The Kco slope differs more between stages of the disease than any other test but further analysis showed that correlations between the Kco slope and the stage of the disease or between the slope and the percentage of lung infiltration, as judged from the radiograph, were not significant statistically.

In considering routine lung function tests from patients, any result two standard deviations or more below the predicted value was classified as "abnormal". Similarly, in classifying the change in Kco slope with exercise, any slope two standard deviations or more below the mean slope for normal subjects was considered "abnormal". On entry to the study, 17 of the 21 patients were found to have normal values for $F E V_{1}$, lung volumes and transfer factor at rest but the Kco response to exercise was abnormal in eight (table 4). The Kco slope was also abnormal in the four patients who had abnormal lung function tests at rest. In none of the patients was the heart rate response to exercise abnormal.

During the course of the study, 19 of the 21 patients

Table 3 Mean values (as a percentage of predicted values) for function tests in patients

\begin{tabular}{|c|c|c|c|c|c|}
\hline $\begin{array}{l}\text { Stage of } \\
\text { disease }\end{array}$ & $\begin{array}{l}\begin{array}{l}\text { Number of } \\
\text { patients }\end{array} \\
3\end{array}$ & $\begin{array}{l}F E V_{1} \\
(\% \text { of }\end{array}$ & $\begin{array}{l}F V C \\
\text { redicted }\end{array}$ & \multicolumn{2}{|c|}{$\begin{array}{c}T L C \quad K_{C o} \text { slope } \\
\text { ormal values) }\end{array}$} \\
\hline $\begin{array}{l}1 \\
2 \\
3\end{array}$ & $\begin{array}{r}3 \\
7 \\
11\end{array}$ & $\begin{array}{r}118.6 \\
100 \cdot 8 \\
97.5\end{array}$ & $\begin{array}{r}124 \cdot 1 \\
100 \cdot 5 \\
97 \cdot 1\end{array}$ & $\begin{array}{l}78 \cdot 3 \\
85 \cdot 1 \\
83 \cdot 3\end{array}$ & $\begin{array}{l}74 \cdot 0 \\
68 \cdot 0 \\
44 \cdot 2\end{array}$ \\
\hline
\end{tabular}

Table 4 Results from tests on patients on entry to the study

\begin{tabular}{llll}
\hline & \multicolumn{2}{l}{ Routine tests at rest } \\
\cline { 3 - 4 } & & Normal & Abnormal \\
\hline \multirow{2}{*}{ Ko slope on exercise } & Normal & 9 & 0 \\
& Abnormal & 8 & 4 \\
\hline
\end{tabular}

had an abnormal slope at some time and in only two was the Kco slope always within normal limits. Over a period of time, individual slopes fluctuated widely in many patients. The routine lung function tests of nine patients which had been normal became abnormal during the study and in all of these this change in function was anticipated by the Kco slope becoming abnormal while the routine tests were still normal.

Although a change in the chest radiograph was often preceded by a change in the exercise response, no consistent correlations were found between radiographic changes and Kco slopes. Of the six patients with an abnormal exercise response whose radiographs returned to normal, the exercise response returned to normal in three but remained abnormal in three. Of the two who had bilateral hilar adenopathy, only one had a consistently normal exercise response while the other remained abnormal. In three subjects with radiographic evidence of pulmonary fibrosis, routine function tests were abnormal in two but the exercise response was consistently abnormal in all three.

The changes in Kco slope which occurred after treatment with corticosteroids were also inconsistent. Frequently there was a big increase in the exercise response immediately after starting steroid therapy but this was not invariable. In only two patients were other sarcoid lesions present which might be assessed clinically, one patient having lymphadenopathy and the other skin lesions. In both there was some evidence of changes in activity matching changes in the Kco slope.

\section{Discussion}

The factors responsible for the increase in transfer coefficient (KCO) during exercise are not completely understood. More even distribution of ventilation and perfusion is known to occur during exercise in normal subjects but this would only account for a small percentage of the increase. ${ }^{10}$ The distension and recruitment of vessels in the pulmonary capillary bed which occur with an increased cardiac output would result in an increased surface area for diffusion, and indeed both components of the transfer factor, namely the pulmonary capillary blood volume $(\mathrm{Vc})$ and the diffusing capacity of the alveolar membrane (Dm), have been shown to increase during exercise in normal subjects, although there is disagreement on which component increases most. ${ }^{11} 12$ An increase in cardiac output is brought about through an increase in both heart rate and stroke volume, and it has been suggested that transfer factor correlates best with stroke volume, both at rest and during exercise. ${ }^{13}$ The nature of our measurements however only 
allowed us to use heart rate as an index of cardiac output.

This increase in cardiac output with exercise varies in different subjects according to fitness. As we wished to relate the change in transfer factor to a change in cardiac output, we correlated the change in Kco during exercise with heart rate rather than with oxygen uptake. This also helped to keep the test simple and non-invasive. There is no evidence from this study that the Kco reaches a plateau in normal subjects before the maximal heart rate is reached as has been previously suggested. ${ }^{1314}$ Although the resting transfer factor decreased with age in our normal group, the slope of the response did not change significantly with age. This allowed us to combine the Kco response data from our normal subjects and also to ignore age differences in the patient group.

Our finding that the Kco failed to increase normally in many patients with normal routine lung function tests suggests that this may be a more sensitive index of impaired function. A large increase in the heart rate response to exercise could result in a low slope of the Kco index, but the heart rate responses of the patients were within normal limits for the loads used. Thus the low slopes were caused by small changes in KCO rather than large increases in heart rate. The effect of pulmonary sarcoidosis on lung function must obviously depend both on the site and magnitude of granulomata, and the location of these may be of more importance than their size and number. It would seem from our results that disease can be present to an extent or in a location which does not interfere with gas transfer at rest but which is sufficient to prevent the normal response of the lung to increasing cardiac output, with a resultant disturbance in gas transfer.

Our findings give further support to the view that abnormal function may exist in patients with normal chest radiographs and so it is perhaps not surprising that there was no good correlation between the exercise response and radiographic appearances. Although many of the patients showed a change in their Kco slope after corticosteroid treatment, there were insufficient numbers in this study to establish if those showing a change were those who gained most benefit from steroids in the long term.

There is still no reliable measure of "activity" of the disease process in pulmonary sarcoidosis with which we would correlate the exercise response. Although the level of serum angiotensin converting enzyme has been suggested as an index, ${ }^{15} 16$ this has not yet been firmly established as a measure of change in the disease. Clinical experience of patients with sarcoidosis, however, has shown that it is often a prolonged disease with fluctuating changes and against this background it is not surprising that the Kco response fluctuated widely in many patients during the study. In contrast, in the patients with radiographic evidence of pulmonary fibrosis in whom the disease had apparently not changed over several years, the Kco response was low and did not fluctuate.

We conclude that the change in transfer coefficient with exercise appears to be a sensitive measure of $\vec{\omega}$ disturbed pulmonary function and thus a useful additional indicator of disease activity especially in $\vec{x}$ the absence of radiographic changes or alterations in $\underset{v}{\omega}$ routine lung function tests.

\section{References}

${ }^{1}$ Marshall R, Smellie H, Baylis JH, Hoyle C, Bates DV. Pulmonary function in sarcoidosis. Thorax 1958;13:48- T 58.

${ }^{2}$ Sharma OP, Colp C, Williams MH. Course of pulmonary sarcoidosis with and without corticosteroid therapy as determined by pulmonary function studies. $\mathrm{Am} \mathrm{J} \mathrm{Med}$ 1966;41:541-51.

3 Turiaf J, Basset G, Georges R. Données a long terme de l'exploration functionelle respiratoire chez les sujets guéris de sarcoïdose pulmonaire. Poumon Coeur 1969; 25:1-15.

${ }^{4}$ Hamer NAJ. Changes in the components of the diffusing capacity in pulmonary sarcoidosis. Thorax 1963;18: 275-87.

5 Marshall R, Karlish AJ. Lung function in sarcoidosis. Thorax $1971 ; 26: 402-5$.

- Levinson RS, Metzger LF, Stanley NN et al. Airway function in sarcoidosis. Am J Med 1977;62:51-9.

7 Radwan L, Grebska E, Koziorowski A. Small airways function in pulmonary sarcoidosis. Scand $J$ Respir Dis $1978 ; 59: 37-43$.

${ }^{8}$ Cotes JE. Lung function. Fourth edition. Oxford: Blackwell Scientific Publications, 1979:239-44.

${ }^{9}$ Siltzbach LE. Pulmonary sarcoidosis. Am J Surg 1955;89: 556-68.

${ }^{10}$ Anderson TW. Studies in pulmonary diffusion in man. $\mathrm{PhD}$ Thesis, University of Toronto, Toronto, Ontario, 1967.

11 Johnson RL, Taylor HF, Lawson WH. Maximal diffusing capacity of the lung for carbon monoxide. $J$ Clin Invest $1965 ; 44: 349-55$.

12 Anderson TW, Shephard RJ. The effects of hyperventilation and exercise upon the pulmonary diffusing capacity. Respiration 1968;25:465-84.

13 Bjure J. Pulmonary diffusing capacity for carbon monoxide $N$ in relation to cardiac output in man. Scand J Clin Invest 1965;17: Suppl 81.

14 Freyschuss U, Holmgren A. The variation of DLco with increasing oxygen uptake during exercise in healthy ${ }^{\circ}$ ordinarily untrained young men and women. Acta

Physiol Scand 1965;65:193-206.
15 Turton CWG, Grundy E, Firth G, Mitchell D, Rigden BG, Turner-Warwick $M$. Value of measuring serum angiotensin I converting enzyme and serum lipozyme in the management of sarcoidosis. Thorax 1979;34:57-62.

${ }^{16}$ Studdy P, Bird R, James DG, Sherlock S. Serum angio-음 tensin-converting enzyme (SACE) in sarcoidosis and other granulomatous disorders. Lancet 1978;2:1331-4. 